\title{
PAPER
}

\section{Electrophysiological evidence for a defect in the processing of temporal sound patterns in multiple sclerosis}

\author{
S J Jones, L Sprague, M Vaz Pato
}

See end of article for authors' affiliations

.....................

Correspondence to: Dr S J Jones, Department of Clinical Neurophysiology,

The National Hospital for

Neurology and

Neurosurgery, Queen

Square, London

WCIN 3BG, UK

sijones@ion.ucl.ac.uk

Received

17 October 2001

In revised form 6 June

2002

Accepted 16 July 2002

\begin{abstract}
Objectives: To assess the processing of spectrotemporal sound patterns in multiple sclerosis by using auditory evoked potentials (AEPs) to complex harmonic tones.

Methods: 22 patients with definite multiple sclerosis but mild disability and no auditory complaints were compared with 15 normal controls. Short latency AEPs were recorded using standard methods. Long latency AEPs were recorded to synthesised musical instrument tones, at onset every two seconds, at abrupt frequency changes every two seconds, and at the end of a two second period of $16 / \mathrm{s}$ frequency changes. The subjects were inattentive but awake, reading irrelevant material.

Results: Short latency AEPs were abnormal in only 4 of 22 patients, whereas long latency AEPs were abnormal to one or more stimuli in 17 of 22. No significant latency prolongation was seen in response to onset and infrequent frequency changes $(P 1, N 1, P 2)$ but the potentials at the end of $16 / \mathrm{s}$ frequency modulations, particularly the P2 peaking approximately $200 \mathrm{~ms}$ after the next expected change, were significantly delayed.

Conclusion: The delayed responses appear to be a mild disorder in the processing of change in temporal sound patterns. The delay may be conceived of as extra time taken to compare the incoming sound with the contents of a temporally ordered sensory memory store (the long auditory store or echoic memory), which generates a response when the next expected frequency change fails to occur. The defect cannot be ascribed to lesions of the afferent pathways and so may be due to disseminated brain lesions visible or invisible on magnetic resonance imaging.
\end{abstract}

A large proportion of patients with established multiple sclerosis (MS) have lesions of central auditory pathways, which can be shown by using short latency auditory evoked potentials (AEPs). ${ }^{1}$ Abnormalities are also often observed in long latency event related potentials (ERPs). These, however, cannot usually be ascribed to afferent pathway lesions but presumably to localised or diffuse lesions within the brain. ${ }^{2}$ Most patients in the advanced stages of MS exhibit some degree of cognitive impairment. ${ }^{3}$ Minor cognitive deficits have also been noted in the early stages, for example, in the performance of verbal memory and abstract reasoning tasks. ${ }^{4}$ In a group of mildly affected MS patients whose clinical symptoms were entirely attributable to disease of the spinal cord, the P3 component of the ERP was yet found to be significantly altered as compared with control subjects during performance of auditory and visual working memory tasks. ${ }^{5}$

An earlier ERP component reflecting short term memory processes is the mismatch negativity. ${ }^{6}$ This potential is elicited automatically (that is, not requiring the conscious attention of the subject) by discrete sounds that differ in some respect from the preceding sequence of sounds. The mismatch negativity appears to depend on retention of the sounds in a sensory memory store, the long auditory store or echoic memory, which decays over a period of a few seconds. ${ }^{7}$ The chief distinction between the long auditory store and verbal working memory is that in the former sounds are represented in a precategorical state, effectively as an acoustic image. It is arguable, however, that verbal working memory may depend to some degree on the "rehearsal" of material through precategorical levels of acoustic storage.

From our previous studies of long latency AEPs to complex harmonic tones (synthesised musical instrument sounds) ( $^{8-10}$ we have distinguished at least two neuronal populations of the supratemporal cortex, responsive to different types of change in the spectrotemporal structure of the sound. A negative potential peaking at approximately $90 \mathrm{~ms}$ and a positivity at $160 \mathrm{~ms}$ are produced by sudden, infrequently occurring changes in the distribution of energy across the audible frequency spectrum. These were termed "change-type" $\mathrm{Nl}$ (CN1) and CP2 components. Similar responses were described in the early literature to continuous pure tones (reviewed by Näätänen and Picton ${ }^{11}$ ) and an apparently similar "acoustic change complex" has recently been described in the context of speech sounds. ${ }^{12}$ The $\mathrm{C}$ potentials are highly sensitive to the rate at which spectral energy changes occur. When the frequencies of the tone were modulated by approximately $\pm 12 \%$ at a rate of 16 changes/s the $C$ potentials were made almost completely refractory but superficially similar $\mathrm{Nl}$ and P2 potentials of slightly longer latency, and more anterior distribution on the scalp, were produced on resumption of a steady tone." ${ }^{13}$ These were termed "mismatch-type" $\mathrm{Nl}$ (MN1) and MP2 components, on account (we have argued ${ }^{13}$ ) of their likely close relation to the mismatch negativity. The amplitudes of the $\mathrm{CNI}$ and the MNl were found to depend to comparable degrees on the time for which the preceding sound pattern (steady for the $\mathrm{CNl}$, rapidly changing for the MN1) had been present, increasing with the duration of the sound for at least 4.5 seconds. ${ }^{9}$ This suggested that responses of maximal amplitude may be generated by the appropriate change when the long auditory store is "full" with a particular sound pattern.

In the present study we examined the $\mathrm{C}$ and $\mathrm{M}$ potentials, together with the conventional $\mathrm{Pl}, \mathrm{Nl}$, and $\mathrm{P} 2$ components

Abbreviations: AEP, auditory evoked potential; ERP, event related potential; MIDI, musical instrument digital interface; MRI, magnetic resonance imaging; $M S$, multiple sclerosis 

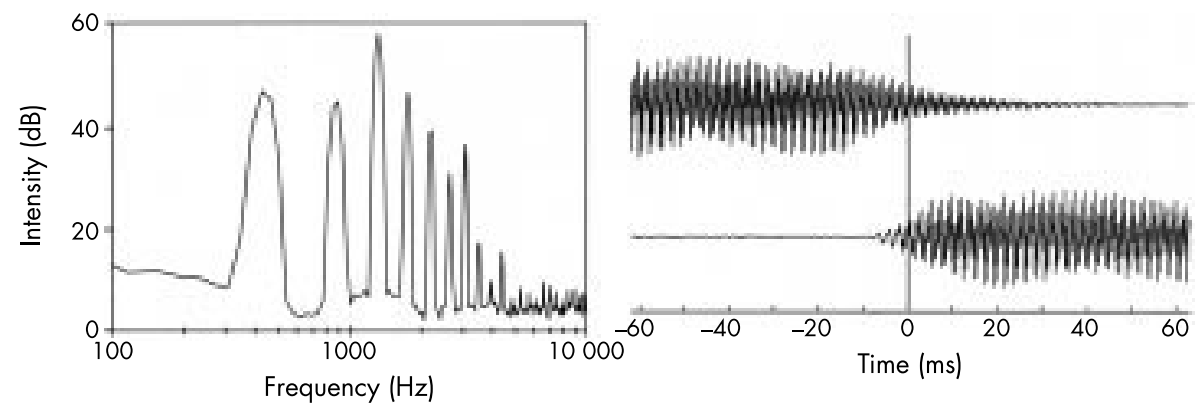

Figure 1 (Upper) Frequency spectrum of clarinet tone, fundamental frequency $440 \mathrm{~Hz}$, and envelope showing extent of overlap between consecutive tones. (Middle) Recording montage. Ref, reference electrode. (Bottom) Stimulus conditions: 1 , onset every two seconds (fundamental $440 \mathrm{~Hz}$, tone on for one second, off for one second); 2 , frequency change every two seconds (fundamental $440 \mathrm{~Hz}$ to $494 \mathrm{~Hz}$ and back); 3 , end of two seconds of $16 / \mathrm{s}$ frequency oscillation (440 Hz to $494 \mathrm{~Hz}$ and back) followed by one second of steady

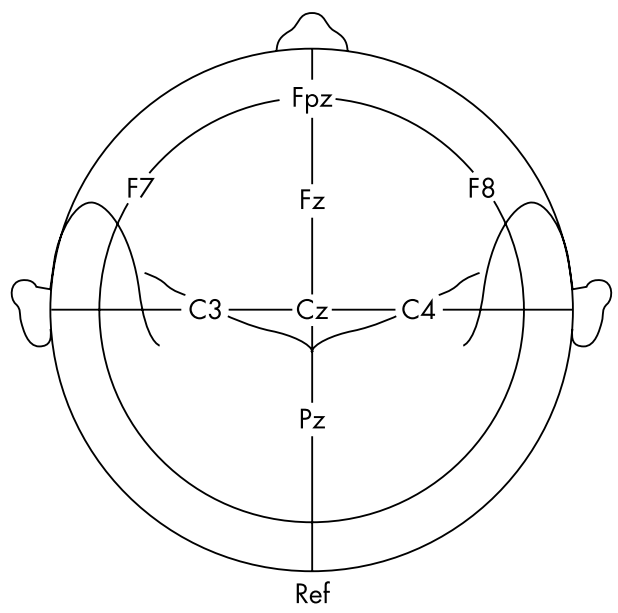
tone.

evoked at the onset of the tone, in a group of patients with relatively mild MS. We consider how the findings may suggest a defect in the processing of temporal sound patterns and may be related to the working memory impairment.

\section{MATERIAL AND METHODS}

The study was approved by the local ethical committee and all subjects gave their informed consent according to the Declaration of Helsinki. Recordings were initially obtained from 38 patients with definite or suspected MS, referred to the Department of Clinical Neurophysiology of the National Hospital for Neurology and Neurosurgery for investigative tests. The patients in the final group were 22 whose condition, after neurological examination and laboratory tests (including evoked potentials and magnetic resonance imaging (MRI)), was diagnosed as definite MS. ${ }^{14}$ Twelve female patients and 10 male patients were aged 21-58 years, mean 42.0 (9.1) years. The diagnosis was of relapsing/remitting MS in 15 cases, primary progressive MS in 5 , and secondary progressive MS in 2. The duration of symptoms ranged from 5 months to 39 years. None of the patients had any significant history of hearing impairment. The control group comprised 15 volunteers, 8 women and 7 men aged 21-49 years, mean 35.7 (7.3) years, with no significant history of hearing impairment or neurological disease. Long latency AEPs were recorded in a quiet room while the subjects sat in a reclining chair and read a magazine or book. The duration of each recording was approximately one hour. Conventional short latency $(<10 \mathrm{~ms})$ AEPs were also recorded to clicks delivered at 10/s to either ear and compared with results from age and sex matched laboratory controls.

The complex harmonic tones were created by a Yamaha MU10 tone generator (Yamaha Corporation, Hamamatsu, Japan) and controlled by an IBM compatible PC. The stimulus sequences were created using Midisoft Recording Studio software (Diamond Recording Systems, Bellevue, Washington, USA), stored as general musical instrument digital interface (MIDI) files and played using Cubasis (Steinberg Soft and Hardware, Hamburg, Germany). The left and right output channels were split, one being used for the stimulus signal (presented to the left and right ears in separate runs, with a fixed intensity 45-50 dB above the threshold of the control subjects) and the other converted to a square wave pulse to 
Table 1 Latency measures ( $\mathrm{ms}$ ) in each group and normal latency limits

\begin{tabular}{|c|c|c|c|c|c|c|}
\hline \multirow[b]{2}{*}{ Potential } & \multirow[b]{2}{*}{ Ear } & \multirow[b]{2}{*}{ Controls $(n=15)$} & \multicolumn{3}{|c|}{ Normal limits } & \multirow[b]{2}{*}{ Patients $(n=22)$} \\
\hline & & & Absolute & Left-right & Interresponse & \\
\hline \multicolumn{7}{|c|}{ Responses to onset (O) } \\
\hline \multirow[t]{2}{*}{ OP1 } & Left & $40.6(9.7)$ & 69.7 & 23.6 & & $36.8(7.9)$ \\
\hline & Right & $43.6(9.2)$ & 71.2 & -29.8 & & 38.616 .7 \\
\hline \multirow{2}{*}{ ON1 } & Left & $81.2(7.5)$ & 103.6 & 14.0 & M-O 61.9 & $82.7(8.9)$ \\
\hline & Right & $86.2(7.4)$ & 108.3 & -24.0 & M-O 63.2 & $85.9(9.2)$ \\
\hline \multirow[t]{2}{*}{ OP2 } & Left & $155.0(13.4)$ & 195.2 & 28.8 & M-O 85.6 & $157.2(19.8)$ \\
\hline & Right & $160.3(16.3)$ & 209.1 & -39.4 & M-O 101.4 & $158.5(16.6)$ \\
\hline \multicolumn{7}{|c|}{ Responses to frequency change (C) } \\
\hline \multirow[t]{2}{*}{$\mathrm{CP} 1$} & Left & $51.4(8.2)$ & 76.0 & 25.9 & & $49.7(8.0)$ \\
\hline & Right & $51.0(8.9)$ & 77.7 & -25.1 & & $50.5(4.7)$ \\
\hline \multirow[t]{2}{*}{$\mathrm{CNI}$} & Left & $91.3(5.0)$ & 106.3 & 17.2 & C-O 28.8 & $91.9(7.4)$ \\
\hline & Right & $93.3(8.6)$ & 119.3 & -21.7 & C-O 34.3 & $96.1(8.2)$ \\
\hline \multirow[t]{2}{*}{$\mathrm{CP} 2$} & Left & $168.7(11.3)$ & 202.7 & 24.2 & C-O 50.0 & $172.6(13.3)$ \\
\hline & Right & $173.3(12.7)$ & 211.4 & -33.4 & C-O 58.9 & $175.2(12.3)$ \\
\hline \multicolumn{7}{|c|}{ Responses at the end of oscillatory frequency changes $(M)$} \\
\hline \multirow[t]{2}{*}{ MN1 } & Left & $106.7(8.2)$ & 131.3 & 21.6 & M-C 38.4 & $114.8(14.0)^{*}$ \\
\hline & Right & $110.1(12.0)$ & 146.1 & -28.5 & M-C 53.2 & $116.2(12.6)$ \\
\hline \multirow[t]{2}{*}{ MP2 } & Left & $187.5(10.6)$ & 219.3 & 21.3 & M-C 55.4 & $207.2(18.1)^{* *}$ \\
\hline & Right & $196.3(15.3)$ & 242.2 & -38.9 & M-C 78.3 & $212.4(17.0)^{* *}$ \\
\hline
\end{tabular}

trigger the recording apparatus. The frequency spectra of the tones were determined by fast Fourier transform (Pico Technology, Hardwick, UK; fig l upper) and their temporal envelopes were examined. The rise time of the tones was approximately $15 \mathrm{~ms}$ and their decay was roughly exponential with a half life of approximately $15 \mathrm{~ms}$ (fig 1). Consecutive tones overlapped so as to produce a smooth transition without any perceptible click or bulge.

Silver/silver chloride disc electrodes were attached to the scalp with paste at locations $\mathrm{Fpz}, \mathrm{Fz}, \mathrm{Cz}$, and $\mathrm{Pz}$ on the sagittal midline and lateral locations C3, C4, F7, and F8 of the 10-20 System (fig 1 middle). The reference electrode was on the dorsum of the neck at the base of the skull. Amplification was by CED 1902 amplifiers (Cambridge Electronic Design, Cambridge, UK) and analogue to digital conversion was by a CED 1401 Plus. The recording bandwidth was between $1 \mathrm{~Hz}$ and $200 \mathrm{~Hz}$ (corner frequencies). Amplified signals were digitised at 1000 points/s for $500 \mathrm{~ms}$ starting $50 \mathrm{~ms}$ before each stimulus change. There were three stimulus conditions, each repeated three times for either ear (fig l lower). The first condition was the onset of a tone of clarinet timbre with a fundamental frequency of $440 \mathrm{~Hz}$. Each tone was presented for one second and was followed by a silent interval of one second. In the second condition, every two seconds a continuous tone of clarinet timbre abruptly changed all its frequencies in geometric proportion, the fundamental changing from $440 \mathrm{~Hz}$ to $494 \mathrm{~Hz}$ and back. In the third condition a continuous tone of clarinet timbre oscillated between the same two frequencies at a rate of 16 changes/s for two seconds before coming to rest on the higher tone for one second (in this condition the trigger occurred $50 \mathrm{~ms}$ before the next expected change). Fifty responses were averaged in each run and the three averaged responses for each stimulus condition were combined into grand average waveforms. $\mathrm{Pl}, \mathrm{Nl}$, and $\mathrm{P} 2$ peaks were determined by visual inspection of the waveforms at Fz, their latencies measured from the midpoint of the rise time of the tones. The amplitudes of $\mathrm{Pl}$ and $\mathrm{Nl}$ were measured from the prestimulus baseline, while P2 amplitude was measured from the peak of Nl. Normal limits were defined as the mean (3 SD) of the control group, calculated directly for absolute latency and interaural latency difference measurements and after logarithmic transformation for amplitudes. Normal limits were also calculated for left to right amplitude ratios and latency differences between the three response types. Groups were compared by the Mann-Whitney U test.

\section{RESULTS}

\section{Routine evoked potential and MRI findings}

Abnormalities of routine visual or somatosensory evoked potentials were seen in 18 of 22 patients. Short latency AEPs, however, were abnormal in only 4 of 22 . Two additional patients had equivocally abnormal short latency AEPs, in one of them suggesting a mild peripheral hearing defect. On T2 weighted MRI, disseminated brain abnormalities compatible with demyelination were seen in 20 of 22 patients. In cases 2 and 21 (both with relapsing/remitting MS diagnosed on clinical and evoked potential criteria) the brain images were reported to be inconclusive and normal, respectively. In no instances did the MRI abnormalities appear specifically to involve auditory structures of the brain.

\section{Long latency AEPs}

Normative data

Reproducible responses to each of the three stimulus types were recorded in every subject. A Pl potential peaking at approximately $50 \mathrm{~ms}$ was present in the responses to onset (OP1) and frequency change $(\mathrm{CPl})$ but not at the end of oscillatory frequency changes. $\mathrm{Nl}$ potentials at $65-145 \mathrm{~ms}$ and $\mathrm{P} 2$ potentials at $120-260 \mathrm{~ms}$ were present to all three stimuli, termed ON1/OP2 (onset), CP1/CP2 (frequency change), and $\mathrm{MN1/MP2} \mathrm{(mismatch-type} \mathrm{at} \mathrm{the} \mathrm{end} \mathrm{of} \mathrm{frequency} \mathrm{oscillation).}$ The $\mathrm{C}$ potentials were on average $5-15 \mathrm{~ms}$ longer in latency than the $\mathrm{O}$ potentials and the $\mathrm{M}$ potentials were 15-25 ms longer in latency than the $\mathrm{C}$ potentials (table 1). The MN1 and MP2 peaks were consistently largest at $\mathrm{Fz}$, while the $\mathrm{O}$ and $\mathrm{C}$ potentials were of comparable magnitude at $\mathrm{Fz}$ and $\mathrm{Cz}$ (the amplitudes used for analysis were all measured at $\mathrm{Fz}$; table 2). No significant differences were found between the responses to left and right ear stimulation, nor were there any significant amplitude asymmetries between corresponding left and right sided electrodes (however, for left ear stimulation the N1 and P2 amplitudes were on average larger at right sided electrodes in 12 of 12 comparisons $(3$ stimulus conditions $\times 2$ components $\times 2$ electrode pairs), while for right ear stimulation the N1 and P2 amplitudes were larger on the right in 9 of 12 comparisons).

\section{Individual patient data}

Measurable responses were also recorded to all three stimulus types in every patient. When compared with the limits of the control group (mean (3 SD); table 1 and table 2), 17 of the 
Table 2 Amplitude measures $(\mu \mathrm{V})$ and normal limits. The $\mathrm{N} 1$ peaks were measured from the prestimulus baseline and the $\mathrm{P} 2$ peaks from $\mathrm{N} 1$

\begin{tabular}{|c|c|c|c|c|c|}
\hline \multirow[b]{2}{*}{ Potential } & \multirow[b]{2}{*}{ Ear } & \multirow[b]{2}{*}{ Controls $(n=15)$} & \multicolumn{2}{|c|}{ Normal limits } & \multirow[b]{2}{*}{ Patients $(n=22)$} \\
\hline & & & Absolute & Ratio left:right & \\
\hline \multicolumn{6}{|c|}{ Responses to onset (O) } \\
\hline \multirow[t]{2}{*}{ ON1 } & Left & $5.9(1.7)$ & 2.6 & 0.35 & $5.0(2.1)$ \\
\hline & Right & $6.3(1.8)$ & 2.3 & 2.62 & $5.4(2.2)$ \\
\hline \multirow[t]{2}{*}{ OP2 } & Left & $11.4(2.6)$ & 5.6 & 0.58 & $9.0(3.2)^{*}$ \\
\hline & Right & $11.5(2.7)$ & 5.4 & 1.70 & $9.4(2.8)^{*}$ \\
\hline \multicolumn{6}{|c|}{ Responses to frequency change (C) } \\
\hline \multirow[t]{2}{*}{$\mathrm{CN1}$} & Left & $7.1(2.1)$ & 2.5 & 0.35 & $6.3(2.2)$ \\
\hline & Right & $7.1(2.4)$ & 1.9 & 3.00 & $6.0(2.4)$ \\
\hline \multirow[t]{2}{*}{$\mathrm{CP} 2$} & Left & $13.2(3.3)$ & 5.8 & 0.58 & $11.2(3.5)$ \\
\hline & Right & $12.8(4.1)$ & 4.4 & 1.92 & $10.9(3.5)$ \\
\hline \multicolumn{6}{|c|}{ Responses at the end of oscillatory frequency changes (M) } \\
\hline \multirow[t]{2}{*}{ MN1 } & Left & $4.2(2.1)$ & 0.8 & 0.26 & $3.8(2.1)$ \\
\hline & Right & $4.2(1.9)$ & 0.9 & 3.62 & $3.9(2.1)$ \\
\hline \multirow[t]{2}{*}{ MP2 } & Left & $9.7(3.1)$ & 3.5 & 0.37 & $8.5(3.1)$ \\
\hline & Right & $8.4(3.9)$ & 2.0 & 3.82 & $8.0(2.7)$ \\
\hline
\end{tabular}

Data are mean (SD). Normal limits are $-3 S D$ (absolute), mean $\pm 3 S D$ (ratio left: right). Significant intergroup differences (Mann-Whitney U test, two tailed, before Bonferroni correction): * $p<0.05$.

patients with MS had one or more long latency AEP measures that were outside the normal range, in absolute terms, in terms of the interaural latency difference or amplitude ratio, or in terms of the latency difference between the three response types (table 3 ). Abnormalities of the $\mathrm{O}$ potentials were seen in 10 patients, of the $C$ potentials in 6 , and of the $M$ potentials in 10. Latency abnormalities were present in 1,4 , and 9 patients, respectively.

In no patients were the long latency AEPs abnormal to all three stimulus types in the same ear. Among the four patients with abnormal short latency AEPs, one with bilateral involvement had abnormal long latency responses to onset on both sides and to frequency change on the left. Two patients had abnormal long latency AEPs only to stimuli delivered to the ear contralateral to that from which the short latency AEPs were abnormal. There was no apparent association, therefore, between long latency AEP abnormalities and lesions of the afferent auditory pathways suggested by short latency AEPs.

\section{Intergroup latency comparisons}

When the two groups were statistically compared using the Mann-Whitney U test, no significant latency differences were found for either the onset responses or the responses to changes of frequency (table 1). Significant differences were observed, however, in the responses at the end of frequency oscillation, the MP2 being significantly delayed in the patient group to stimulation of either ear, while the MNl was significantly delayed on the left and just non-significantly on the right. After Bonferroni correction for 16 intergroup latency comparisons, the effect on the MP2 remained significant for both sides. When the group mean waveforms are superimposed (fig 2), the ON1, OP2, $\mathrm{CN1}$, and $\mathrm{CP} 2$ peaks are

Table 3 Auditory evoked potential abnormalities in the patient group, with criteria of low amplitude, prolonged latency, and increased left to right and interresponse latency differences. All other potentials were within normal limits (mean $\pm 3 S D$ )

\begin{tabular}{|c|c|c|c|c|c|c|c|c|c|c|}
\hline \multirow[b]{3}{*}{ Patient } & \multirow[b]{3}{*}{ Sex } & \multirow{3}{*}{$\begin{array}{l}\text { Age } \\
\text { (years) }\end{array}$} & \multirow{2}{*}{\multicolumn{2}{|c|}{ Short latency responses }} & \multicolumn{6}{|c|}{ Long latency responses } \\
\hline & & & & & \multicolumn{2}{|l|}{ Onset } & \multicolumn{2}{|c|}{ Frequency change } & \multicolumn{2}{|c|}{ End of oscillation } \\
\hline & & & Left & Right & Left & Right & Left & Right & Left & Right \\
\hline 1 & Male & $47 \dagger$ & & Abnormal & & & CN1 & & & \\
\hline 2 & Female & $49 \dagger$ & & & & & & & & \\
\hline 3 & Female & 33 & & & ONI & & & & & \\
\hline 4 & Female & 53 & & & & & & & & \\
\hline $5^{*}$ & Female & $58 \dagger$ & & & ONI & & & & MP2 & \\
\hline 6 & Female & 36 & & & & & & $\mathrm{CN} 1$ & & \\
\hline 7 & Male† & 38 & & & & & & & MN1P2 & \\
\hline $8 *$ & Female & 52 & & & OP2 & & $\mathrm{CNI}$ & CN1 & & \\
\hline 9 & Female & $33 \dagger$ & & & & & & & & \\
\hline 10 & Male & $53 \dagger$ & & & & & & & MP2 & MP2 \\
\hline 11 & Male & 44 & & & & ONI & & & & MN1P2 \\
\hline 12 & Female & 38 & Abnormal & Abnormal & ON1P2 & ON1P2 & CN1P2 & & & \\
\hline $13^{*}$ & Male & 35 & & Abnormal & & & & & & MP2 \\
\hline 14 & Female & 38 & & & & ONI & CP2 & & MP2 & \\
\hline 15 & Male & $35 \dagger$ & & Abnormal & & & & & MN1P2 & \\
\hline $16^{*}$ & Male & 45 & & & & & & & & \\
\hline $17^{*}$ & Female & 49 & & & & & & & & \\
\hline $18^{*}$ & Male & 33 & & & OP2 & & & & & MN1 \\
\hline $19 *$ & Female & 52 & & & & & & & MP2 & \\
\hline 20 & Female & 46 & & & OP2 & & & & MN1 & \\
\hline 21 & Male & 36 & & & ON1 & & & & & \\
\hline 22 & Male & 21 & & & & OP2 & & CN1P2 & & \\
\hline
\end{tabular}



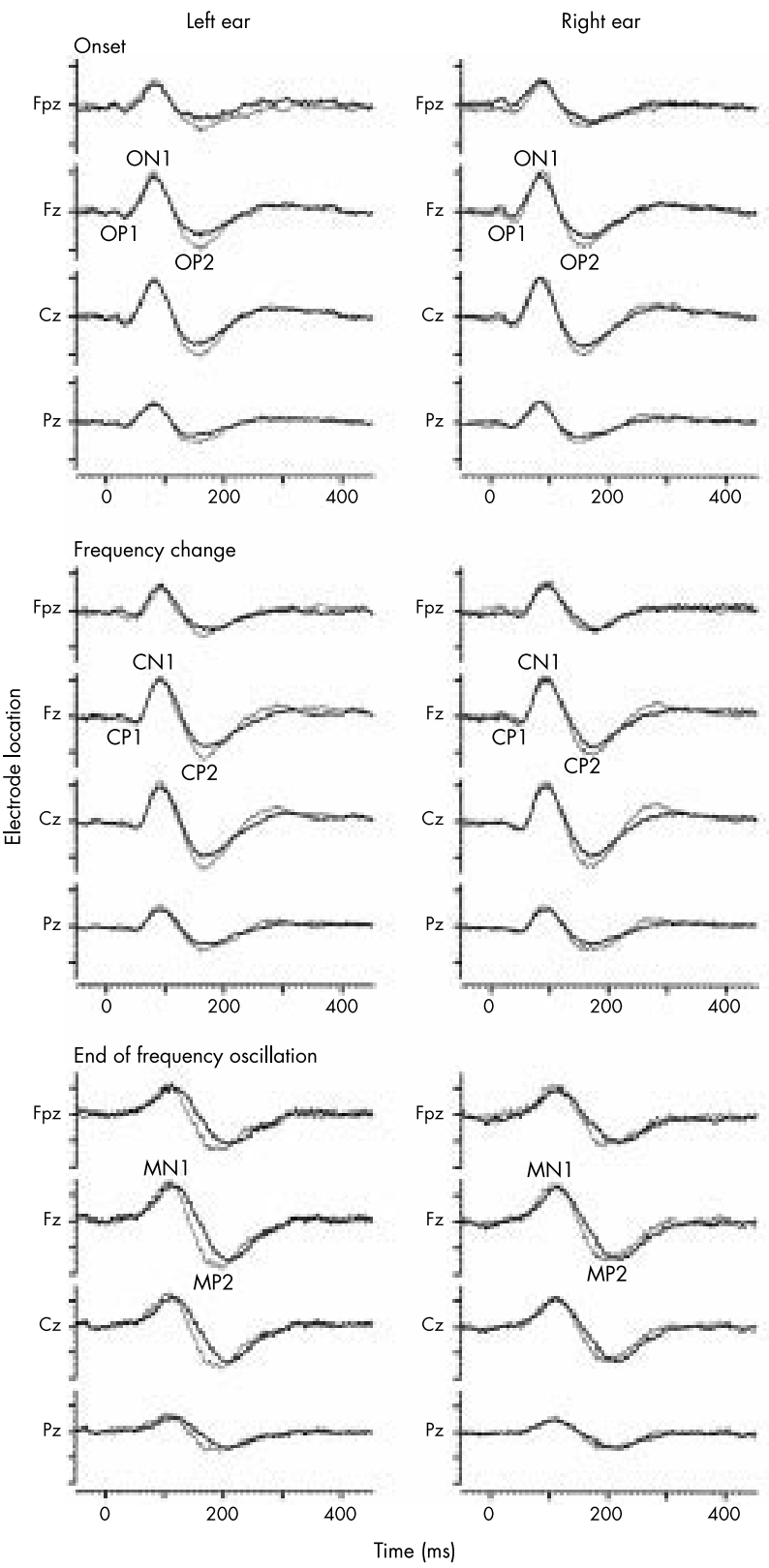

Figure 2 Superimposition of group mean responses of the patients with multiple sclerosis (darker line) and the controls (paler line) to left and right ear stimulation, sagittal midline electrodes. Note the close correspondence between peak latencies for the two groups in the responses to onset $(\mathrm{O})$ and frequency change $(\mathrm{C})$ but the slight delay at the end of frequency oscillation $(M)$ of the $M N 1$ in the multiple sclerosis group and the more pronounced delay of the MP2.

seen to correspond closely in latency between patients and controls, while a small latency disparity is suggested for the $\mathrm{MNl}$ and a more pronounced disparity is evident for the MP2.

The latency differences between $\mathrm{O}, \mathrm{C}$, and $\mathrm{M}$ potentials were also compared between groups (table 4). No significant intergroup effects were observed for the $\mathrm{C}$-O differences. However, the MP2-OP2 and MP2-CP2 differences were all significantly larger in the patient group $(\mathrm{p}<0.01$ or better) while the MNl-CNl latency difference was significantly larger in the patient group for responses to stimulation of the left ear only $(\mathrm{p}<0.05)$.

\section{Intergroup amplitude comparisons}

All AEP amplitudes were on average slightly lower in the patients than in the controls (table 2). Before Bonferroni cor- rection this reached significance $(\mathrm{p}<0.05)$ for the left and right ear OP2 but after Bonferroni correction the differences were all non-significant.

Effect of duration and classification of disease

No significant differences were found when seven patients with disease duration longer than six years were compared with the remainder of the patient group. Most latencies were longer on average in seven patients classified as primary or secondary progressive MS, as compared with the remainder classified as having relapsing/remitting MS, but the differences were all non-significant.

\section{DISCUSSION}

We have previously described the properties of long latency AEPs to spectrotemporal modulation of complex tones in normal subjects. ${ }^{8-1013}$ One possible clinical application of these techniques has been explored in a group of patients with brain injury $^{15}$ to establish the degree to which cortical mechanisms for processing complex sounds may be preserved and to what degree this is correlated with behavioural responsiveness.

In the present study as in previous ones, the $\mathrm{M}$ potentials were distributed slightly more anteriorly on the scalp than the $\mathrm{C}$ and $\mathrm{O}$ potentials, whose distributions were similar to one another. On average most responses were slightly larger on the right, although left-right differences were not significant. Our interpretation of the $\mathrm{C}$ potentials is that they reflect a process for analysing the distribution of energy across the spectral envelope, responses being generated when the spectral profile of the sound abruptly changes causing an immediate change in the impression of pitch or timbre (intensity changes have not yet been investigated) ${ }^{10}$ From their similar morphology and scalp distribution, it seems likely that the $\mathrm{O}$ potentials at the onset of the tone from silence largely reflect the same process. The M potentials, on the other hand, are elicited either when an unexpected change occurs in a rapid sequence $^{16}$ or at the moment an expected change fails to occur. $^{13}$ Therefore, whereas the C process seems to be governed purely by the spectral composition over the few seconds preceding the change, the $M$ process is sensitive to the temporal structure.

Somewhat paradoxically, in view of the high incidence of abnormal short latency AEPs in the MS population (although not in the relatively mildly affected patients of the present study), the $\mathrm{N} 1$ and $\mathrm{P} 2$ potentials to clicks and the onset of tone bursts are seldom found to be delayed. ${ }^{17-19}$ One study in which the $\mathrm{N} 1$ and P2 potentials were reportedly affected is that of Giesser et $a l_{,}{ }^{20}$ but this was in demented as compared with non-demented patients. More recently, Hendler et al ${ }^{21}$ found long latency AEPs to be abnormal only in conjunction with bilaterally abnormal short latency potentials. If lesions of the afferent auditory pathway tend to cause conduction delays of only a few milliseconds, it is understandable that this may be insufficient to cause long latency potentials to exceed the normal latency range. It may also be significant that the pathways to the auditory cortex are at least partially bilateral with several decussations, such that input may arrive by more than one route.

The evidence for cognitive dysfunction in MS includes patients in the early stages of the disease. ${ }^{42}$ Some studies have noted a tendency for certain forms of memory to be more affected than others, the emphasis usually being on working memory and retrieval of long term memory. ${ }^{23-30}$ Others, however, have concluded that all memory domains are likely to be impaired ${ }^{31}$ and that visual and auditory modalities are not differentially affected. ${ }^{32}$ Specific deficits noted by some authors include accelerated forgetting ${ }^{33}$ and increased short term memory scanning time. ${ }^{34}$ Follow up studies have observed that cognitive and neurological deficits do not 
Table 4 Comparison of interresponse latency differences between the control and patient groups

\begin{tabular}{|c|c|c|c|c|}
\hline Response types & Potential & Ear & Controls & Patients \\
\hline \multirow[t]{4}{*}{ Frequency change $v$ onset } & \multirow[t]{2}{*}{ CNI-ONI } & Left & $9.9(6.3)$ & $9.2(7.1)$ \\
\hline & & Right & $8.7(8.5)$ & $10.1(7.6)$ \\
\hline & \multirow[t]{2}{*}{ CP2-OP2 } & Left & 13.7 (12.0) & $15.4(13.7)$ \\
\hline & & Right & $13.0(15.3)$ & 16.7 (17.3) \\
\hline \multirow[t]{4}{*}{ End of oscillation $v$ onset } & \multirow[t]{2}{*}{ MNI-ONI } & Left & $25.5(12.1)$ & $32.1(15.8)$ \\
\hline & & Right & $24.0(13.1)$ & 30.3 (13.9) \\
\hline & \multirow[t]{2}{*}{ MP2-OP2 } & Left & 32.5 (17.7) & $50.0(22.4)^{* *}$ \\
\hline & & Right & $36.0(21.8)$ & $53.9(21.0)^{* *}$ \\
\hline \multirow{4}{*}{ End of oscillation $v$ frequency change } & \multirow{2}{*}{ MN1-CN1 } & Left & $15.6(7.6)$ & $22.8(11.8)^{*}$ \\
\hline & & Right & $16.8(12.2)$ & $20.2(16.0)$ \\
\hline & \multirow[t]{2}{*}{ MP2-CP2 } & Left & $18.8(12.2)$ & $34.6(17.3)^{* * *}$ \\
\hline & & Right & $23.0(18.5)$ & $37.2(18.5)^{* *}$ \\
\hline
\end{tabular}

necessarily develop in parallel, ${ }^{4}$ suggesting that the former may be caused by disseminated cerebral lesions that are neurologically silent. Some correlation has been noted between the degree of cognitive impairment and the lesion load seen in MRIs obtained using conventional spin echo sequences. ${ }^{35}$ Others, however, have found that such lesions account for the severity of cognitive impairment only partially ${ }^{36}{ }^{37}$ and that it may be necessary also to postulate dysfunction of the normal appearing white matter. A closer association between MRI lesion load and cognitive performance (as assessed by an auditory verbal learning test) was obtained using a fast fluid attenuated inversion recovery technique, ${ }^{38}$ which resolved many more small perivascular lesions. Functional imaging studies have suggested a hypometabolism of structures including the thalamus and the deep grey matter of the temporal lobe to account for impaired episodic memory performance. ${ }^{39}$

Cognitive ERPs are frequently abnormal in MS, ${ }^{17} 204041$ even in the early stages. ${ }^{2}$ In relatively mildly affected patients a tendency has been noted for responses reflecting auditory working memory to be more impaired than those to similar tasks in the visual modality, the defect being ascribed to dysfunction of the "phonological loop", ${ }^{42}$ which may conceivably involve rehearsal of verbal material through precategorical levels of acoustic storage. However, deficits in ERPs during acquisition and recall of both auditory verbal and visuospatial material have been reported in patients whose clinical presentation was confined to symptoms implicating the spinal cord. ${ }^{5}$ Although the N2 ERP component is frequently reported to be affected in addition to the P3, most ERP studies have noted no significant involvement of the $\mathrm{Nl}$ or P2..$^{17} 1943$

It is remarkable that patients with MS rarely complain of auditory symptoms. In psychoacoustic tests, subtle defects have been recognised that mostly appear to reflect abnormalities of the subcortical auditory pathways. ${ }^{44}$ Abnormalities of interaural time difference discrimination have been frequently reported, particularly in patients with known brainstem lesions, ${ }^{45}$ and one study ${ }^{46}$ found a large proportion of patients with MS who experienced difficulties with a task designed to test the temporal precedence effect in sound localisation. It is understandable that these defects are frequently associated with abnormalities of short latency AEPs, in which the measured conduction delays are of the same order as the temporal discrimination deficit.

Very few attempts have been made to identify the kinds of deficits that may be associated with lesions of higher auditory structures in MS. In one study, ${ }^{47}$ abnormal binaural masking level differences (a test of the perception of interaural phase relations) were always found to be associated with abnormal short and middle latency AEPs but increased temporal gap detection thresholds for monaural sounds ( seen in only 2 of 15 cases) appeared to be specifically related to abnormalities of long latency AEPs. Perhaps more directly relevant to the present study is a report by Rappaport et $a l^{48}$ describing a selective impairment of speech sound recognition in the presence of interrupted background noise. This was interpreted as being predominantly due to damage to the auditory pathways of the forebrain. In normal subjects we have found the latency of the MNl to vary with the strength of perceptual "streaming", a relatively short latency being associated with wider frequency separations between consecutive tones and thus a greater tendency for them to be perceived as forming separate streams. ${ }^{16} \mathrm{~A}$ defect of this mechanism may therefore cause difficulties in the analysis of changing sound patterns such as speech, particularly when interfering sounds are intermittently present.

In conclusion, among a group of patients in the relatively early stages of MS (most of them with a recent diagnosis and not severely physically or cognitively impaired) we have shown a subtle but consistent delay in the cortical responses to the cessation of rapid, repetitive frequency changes but not to the onset of tones or to infrequent changes of frequency. This cannot be attributed to lesions of the afferent auditory pathways and may therefore result from a defect of corticothalamic or corticocortical circuits concerned with analysing the temporal structure of sound sequences. The likelihood that the affected long latency AEPs depend on the retention of sounds in a short term sensory memory store suggests that this disorder may reflect at a lower physiological level the impaired mnemonic precesses that are a common feature of MS.

\section{Authors' affiliations}

S J Jones, L Sprague, M Vaz Pato, The National Hospital for Neurology and Neurosurgery, London, UK

Competing interests. none declared

\section{REFERENCES}

1 Halliday AM. The comparative value of the different evoked potentials and other paraclinical tests in the diagnosis and prognosis of demyelinating disease. In: Halliday AM, ed. Evoked potentials in clinical testing, 2nd edn. Edinburgh: Churchill Livingstone, 1993:467-88.

2 Barrett G, Feinstein A, Jones S, et al. Event-related potentials in the assessment of cognitive function in multiple sclerosis. Electroencephalogr Clin Neurophysiol Suppl 1999;50:469-79.

3 Rao SM. White matter disease and dementia. Brain Cogn 1996:31:250-68.

4 Amato MP, Ponziani G, Pracucci G, et al. Cognitive impairment in early-onset multiple sclerosis. Pattern, predictors, and impact on everyday life in a 4-year follow-up. Arch Neurol 1995;52:168-72.

5 Pelosi L, Geesken JM, Holly M, et al. Working memory impairment in early multiple sclerosis. Evidence from an event-related potential study of patients with clinically isolated myelopathy. Brain 1997;1 20:2039-58. 
6 Picton DW, Alain C, Otten L, et al. Mismatch negativity: different water in the same river. Audiol Neurootol 2000;5:111-39.

7 Cowan N. On short and long auditory stores. Psychol Bull 1984;96:341-70.

8 Jones SJ, Longe O, Vaz Pato M. Auditory evoked potentials to abrupt pitch and timbre change of complex tones. Electrophysiological evidence of "streaming"? Electroencephalogr Clin Neurophysiol 1998; 108:131-42

9 Jones SJ, Vaz Pato M, Sprague L. Spectro-temporal analysis of complex tones: two cortical processes dependent on retention of sounds in the long auditory store. Clin Neurophysiol 2000;111:1569-76.

10 Jones SJ, Perez N. The auditory "C-process": analysing the spectral envelope of complex sounds. Clin Neurophysiol 2001;1 12:965-75.

11 Näätänen R, Picton T. The N1 wave of the human electric and magnetic response to sound: a review and an analysis of the component structure. Psychophysiology 1987;24:375-425.

12 Martin BA, Boothroyd A. Cortical, auditory, evoked potentials in response to change of spectrum and amplitude. J Acoust Soc Am 2000;107:2155-61.

13 Vaz Pato M, Jones SJ. Cortical processing of complex tone stimuli: mismatch negativity at the end of a period of rapid pitch modulation. Cogn Brain Res 1999;7:295-306.

14 Poser CM, Paty DW, Scheinberg L, et al. New diagnostic criteria for multiple sclerosis: guidelines for research protocols. Ann Neurol 1983:13:227-31.

15 Jones SJ, Vaz Pato M, Sprague L, et al. Auditory evoked potentials to spectro-temporal modulation of complex tones in normal subjects and patients with severe brain injury. Brain 2000;123:1007-16.

16 Hung J, Jones SJ, Vaz Pato M. Scalp potentials to pitch change in rapid tone sequences: a correlate of sequential stream segregation. Exp Brain Res 2001;140:56-65.

17 Newton MR, Barrett G, Callanan MM, et al. Cognitive event-related potentials in multiple sclerosis. Brain 1989;112:1637-60.

18 van Dijk JG, Jennekens-Schinkel A, Caekebeke JF, et al. What is the validity of an "abnormal" evoked or event-related potential in MS? Auditory and visual evoked and event-related potentials in multiple sclerosis and normal subjects. J Neurol Sci 1992;109:11-7.

19 Triantafyllou NI, Voumvourakis K, Zalonis I, et al. Cognition in relapsing-remitting multiple sclerosis: a multi-channel event-related potential (P300) study. Acta Neurol Scand 1992;85:10-3.

20 Giesser BS, Schroeder MM, LaRocca NG, et al. Endogenous event-related potentials as indices of dementia in multiple sclerosis patients. Electroencephalogr Clin Neurophysiol 1992;82:320-9.

21 Hendler T, Squires NK, Moore JK, et al. Auditory evoked potentials in multiple sclerosis: correlation with magnetic resonance imaging. J Basic Clin Physiol Pharmacol 1996;7:245-78.

22 Klonoff H, Clark C, Oger J, et al. Neuropsychological performance in patients with mild multiple sclerosis. J Nerv Ment Dis 1991;179:127-31.

23 Litvan I, Grafman J, Vendrell P, et al. Multiple memory deficits in patients with multiple scelerosis: exploring the working memory system. Arch Neurol 1988;45:607-10.

24 Rao S, Leo GJ, Bernardin L, et al. Cognitive dysfunction in multiple sclerosis. I. Frequency, patterns, and prediction. Neurology 1991;41:685-91.

25 Grafman J, Rao S, Bernardin L, et al. Automatic memory processes in patients with multiple sclerosis. Arch Neurol 1991;48:1072-5.

26 Ron MA, Callanan MM, Warrington EK. Cognitive abnormalities in multiple sclerosis: a psychometric and MRI study. Psychol Med 1991;21:59-68.
27 Mahler ME. Behavioural manifestations associated with multiple sclerosis. Psychiatr Clin North Am 1992;15:427-38.

28 Grigsby J, Ayarbe SD, Kravcisin N, et al. Working memory impairment among persons with chronic progressive multiple sclerosis. J Neurol 1994;241:125-31.

29 Arnett PA, Rao SM, Grafman J, et al. Executive functions in multiple sclerosis: an analysis of temporal ordering, semantic encoding, and planning abilities. Neuropsychology 1997;11:535-44.

30 Foong J, Rozewitz L, Quaghebeur G, et al. Executive function in multiple sclerosis. The role of frontal lobe pathology. Brain 1997; 120:15-26.

31 Thornton AE, Raz N. Memory impairment in multiple sclerosis: a quantitative review. Neuropsychology 1997;11:357-66.

32 Diamond BJ, Deluca J, Kim H, et al. The question of disproportionate impairments in visual and auditory information processing in multiple sclerosis. J Clin Exp Neuropsychol 1997;19:34-42.

33 Lokken K, Ferraro FR, Petros T, et al. The effect of importance level, delay, and rate of forgetting on prose recall in multiple sclerosis. Appl Neuropsychol 1999:6:147-53.

34 Janculjak D, Mubrin Z, Brzovic Z, et al. Changes in short-term memory processes in patients with multiple sclerosis. Eur J Neurol 1999;6:663-8.

35 Izquierdo G, Campoy F Jr, Mir J, et al. Memory and learning disturbances in multiple sclerosis. MRI lesions and neurpsychological correlation. Eur J Radiol 1991;13:220-4.

36 Fulton JC, Grossman RI, Udupa J, et al. MR lesion load and cognitive function in patients with relapsing-remitting multiple sclerosis. Am J Neuroradiol 1999;20:1951-5

37 Foong J, Rozewicz L, Chong WK, et al. A comparison of neuropsychological deficits in primary and secondary progressive multiple sclerosis. I Neurol 2000:247:97-101.

38 Moriarty DM, Blackshaw AJ, Talbot PR, et al. Memory dysfunction in multiple sclerosis corresponds to juxtacortical lesion load on fast fluid-attenuated inversion-recovery MR images. Am J Neuroradiol 1999;20: 1956-62

39 Paulesu E, Perani D, Fazio F, et al. Functional basis of memory impairment in multiple sclerosis: a [18F]FDG PET study. Neuroimage 1996;4:87-96

40 Honig LS, Ramsay RE, Sheremata WA. Event-related P300 in multiple sclerosis. Relation to magnetic resonance imaging and cognitive impairment. Arch Neurol 1992;49:44-50.

41 Polich J, Romine JS, Sipe JC, et al. P300 in multiple sclerosis: a preliminary report. Int J Psychophysiol 1992;12:155-63.

42 Ruchkin DS, Grafman J, Krauss GL, et al. Event-related brain potential evidence for a verbal working memory deficit in multiple sclerosis. Brain 1994:117:289-305.

43 Boose MA Cranford JL. Auditory event-related potentials in multiple sclerosis. Am J Otol 1996;17:165-70.

44 Noffsinger D, Olsen WO, Carhart R, et al. Auditory and vestibular aberrations in multiple sclerosis. Acta Otolaryngol Suppl 1972; 303: 1-63.

45 van der Poel JC, Jones SJ, Miller DH. Sound lateralization, brainstem auditory evoked potentials and magnetic resonance imaging in multiple sclerosis. Brain 1988;111:1453-74

46 Cranford JL, Boose M, Moore CA. Tests of the precedence effect in sound localization reveal abnormalities in multiple sclerosis. Ear Hear 1990;11:282-8.

47 Hendler T, Squires NK, Emmerich DS. Psychophysical measures of central auditory dysfunction in multiple sclerosis: neurophysiological and neuroanatomical correlates. Ear Hear 1990;11:403-16.

48 Rappaport JM, Gulliver JM, Phillips DP, et al. Auditory temporal resolution in multiple sclerosis. J Otolaryngol 1994;23:307-24. 